\title{
Patterns and processes of compositional change in a California epibenthic community
}

\author{
Cascade J. B. Sorte ${ }^{1,2,3, *}$, John J. Stachowicz ${ }^{1,2}$ \\ ${ }^{1}$ Department of Evolution and Ecology, University of California, Davis, California 95616, USA \\ ${ }^{2}$ Bodega Marine Laboratory, University of California, Bodega Bay, California 94923, USA \\ ${ }^{3}$ Present address: Department of Environmental, Earth and Ocean Sciences, University of Massachusetts, Boston, \\ Massachusetts 02125, USA
}

\begin{abstract}
As human modifications of the earth's systems have increased, so has interest in understanding past changes in order to predict future ecological trajectories. We compared historical (1969-1971) and contemporary (2005-2009) abundances of species in the marine epibenthic community of Bodega Harbor, California, USA. Between these 2 time periods, we found a decrease in the abundance of native species and an increase in non-native dominance, including of several species that were either rare or absent $\sim 35 \mathrm{yr}$ ago and whose introduction was likely human-mediated. This compositional shift was concurrent with an increase in local water temperature of $\sim 1^{\circ} \mathrm{C}$ over the same interval. To address the potential role of ocean warming in facilitating the increase of the new dominant species and maintaining compositional shifts, we evaluated the correlation between temperature and recruitment for 15 species. We found that recruitment timing and magnitude were positively related to temperature for non-native species but not for native species overall. Combined with previous results suggesting effects of ocean warming on the relative performance of native vs. nonnative species in this community, our study indicates the potential for continued dominance of nonnative species in Bodega Harbor due to local temperature increases. Simultaneously, anthropogenic transport has been responsible for several recent introductions of competitively dominant species, and shifts in contaminant loads or other factors between the 2 time periods could also contribute to compositional shifts, both historically and in the future. Our results highlight the need for studies of these additional factors, as well as the mechanisms underlying their effects on compositional shifts, in order to predict future changes.
\end{abstract}

KEY WORDS: Invasive species - Climate change - Ecological forecasting - Marine ecology · Fouling community

Resale or republication not permitted without written consent of the publisher

\section{INTRODUCTION}

Recent increases in both species introductions and global temperatures have been implicated in causing observed shifts in the composition of communities (Sala et al. 2000, Walther et al. 2002, IPCC 2007a,b). Exploring the direction and potential causes of such shifts by comparing historical and contemporary records can provide insights into the likely trajectories of future biological changes (e.g. Barry et al. 1995, Sagarin et al. 1999, Dijkstra et al. 2007, Knowlton \&
Jackson 2008). Here, we compare the historical and current composition of a marine epibenthic community based on measurements taken $35 \mathrm{yr}$ apart, and we address the relationship between species' responses to temperature variation - specifically, the effects on recruitment patterns - and their observed changes in abundance.

Marine epibenthic communities have been used as model systems for the study of fundamental ecological questions, including those about community assembly, diversity-invasibility relationships, multiple stable 
states, and succession (e.g. Sutherland 1974, Sutherland \& Karlson 1977, Stachowicz et al. 1999). Epibenthic communities are also ideal systems in which to study processes driving and maintaining changes in community composition. Because of the species' relatively short generation times ( $<1 \mathrm{yr})$ and fast turnover rates, large changes can be potentiated over a period of years to decades (Boyd 1972, Sutherland \& Karlson 1977, Dean \& Hurd 1980). In addition, the species differ in their responses to variation in ocean temperatures (e.g. Stachowicz et al. 2002, McCarthy et al. 2007, Epelbaum et al. 2009, Sorte et al. 2010a,b), such as those predicted by global warming scenarios, and epibenthic communities are becoming increasingly dominated by non-native species (e.g. Cohen \& Carlton 1995, Lambert \& Lambert 1998, Harris \& Tyrrell 2001).

Space is a limiting resource in this system (Osman 1977, Stachowicz et al. 1999); thus, processes responsible for space acquisition (including recruitment, growth, and overgrowth competition) play important roles in determining community composition. For individuals of common taxa such as bryozoans and tunicates (sea squirts), initial space acquisition is via recruitment of planktonic larvae that metamorphose into their benthic adult form on either non-living substrata (e.g. human-made docks and natural rocky reefs) or on living substrata (e.g. mussels or solitary sea squirts). Because of the role of recruitment in space acquisition, and because its magnitude and phenology can be temperature-dependent and species-specific (Stachowicz et al. 2002), temperature effects on recruitment have the potential to cause or reinforce changes in the composition of the community.

Specifically, we examined whether the epibenthic community of Bodega Harbor, California has become increasingly dominated by non-native species. We then assessed whether there was evidence of one potential mechanism for such a shift: non-native species responding more favorably to warmer temperatures than natives (Dukes \& Mooney 1999). Both temperatures and invasions have increased worldwide over the past century (Cohen \& Carlton 1995, 1998, Ruiz et al. 1997, Vitousek et al. 1997), which is consistent with the hypothesis that climate change will facilitate the spread of invaders; however, it is difficult to infer causation due to myriad confounding factors. Thus, studies comparing traits and responses of native and non-native species are essential in helping to disentangle the role of environmental changes from that of e.g. increased anthropogenic transport of nonnatives in driving this pattern (e.g. Stachowicz et al. 2002, Fields et al. 2006, Chown et al. 2007, Scheibling \& Gagnon 2009, Sorte et al. 2010a, Willis et al. 2010). There is recent evidence that phenologies of non- native species have shifted concurrently with global increases in air and ocean temperatures (IPCC 2007a): events such as flowering (Willis et al. 2010) and recruitment (Stachowicz et al. 2002) are now occurring earlier in the year, in a direction that could give non-natives an advantage via priority effects (see Shulman et al. 1983) if natives do not respond similarly. We assessed the evidence for this in the Bodega Harbor epibenthic community, specifically asking:

(1) How has the abundance of native vs. non-native species changed in this community over the past $\sim 35 \mathrm{yr}$ ?

(2) Is temperature positively associated with recruitment for species that are increasing in abundance such that this association could underlie or reinforce shifts in abundance?

We also examined the potential role of other environmental factors and discuss the evidence that changes in these factors (as opposed to temperature) could underlie observed community shifts.

\section{MATERIALS AND METHODS}

Study sites. Bodega Harbor $\left(\mathrm{CA}_{i} 38.3290^{\circ} \mathrm{N}\right.$, $123.0581^{\circ} \mathrm{W}$ ) is a strongly marine-influenced harbor, with 55 to $80 \%$ of its water exchanged during each tidal cycle (Boyd 1972) and freshwater input occurring intermittently from streams that form during the winter rainy season. Boyd (1972) studied the epibenthic community of Bodega Harbor at Mason's Marina between February 1969 and March 1971. We compared Boyd's historical data to those we collected between May 2005 and September 2009 at Spud Point Marina, where we monitored environmental parameters, as well as recruitment of epibenthic species and development of the community.

Previous studies have shown that recruitment dynamics (Byrnes \& Stachowicz 2009) and common species on docks (C. Sorte unpubl. data) are similar between Spud Point (our site) and Mason's Marina (Boyd's site), which are $<300 \mathrm{~m}$ apart. Furthermore, we compared species composition on $10 \times 10 \mathrm{~cm}$ experimental settlement plates $(N=4)$ deployed simultaneously at Spud Point and Mason's Marina from June 2006 until January 2007. We found that after 7 mo of community development, there was no difference in native or non-native abundances between the sites ( $t$-test $\mathrm{p}>0.4$; see Fig. $\mathrm{S} 1$ in the supplement at www.int-res.com/articles/suppl/m435p063_supp.pdf). Community development also did not differ between 2 settlement substrata: masonite (used by Boyd 1972) and PVC plastic (used in contemporary studies). A comparison of $N=4$ plates per settlement substrate deployed in June 2010 indicated that there was no 
significant difference in community composition (ANOSIM R $=-0.125, \mathrm{p}=0.829$ ) or in cover of natives, non-natives, or individual species between the substrata ( $t$-test $\mathrm{p}>0.2$; see supplementary Fig. S2). Thus, overall, methods and study sites appear similar, permitting direct comparison of the 2 datasets.

Community composition. We quantified community composition on plastic settling plates deployed in May $(N=7)$ and July $2006(N=8)$. At each deployment date, we prepared a set of $10 \times 10 \mathrm{~cm}$ grey PVC plastic plates that had been sanded to create a rough surface. As in Boyd (1972), plates were suspended horizontally and upside down on a rack deployed $1 \mathrm{~m}$ below the surface of floating docks.

We photographed the community plates in midFebruary 2007 and visually estimated the abundance of each species from the digital photographs. The abundances on the 2006-2007 plates were compared to those on $12 \times 12 \mathrm{~cm}$ masonite plates deployed by Boyd (1972) in May and July 1970 and collected in early March 1971 (Table 12 in Boyd 1972). For both the historical and contemporary data, we calculated the average cover of bare space and of each species across all plates and time points. Due to ambiguity in species identifications, we considered the following as cryptogenic: all hydroid Obelia species, the tunicate Botrylloides sp. in Boyd (1972), and the tunicate Ciona and sponge species from our recent observations. None of these cryptogenic species was abundant $(<7 \%$ cover in total); thus, our main conclusions regarding relative abundance of native and non-native species would not be altered if the cryptogenics' regions of origin could be unambiguously determined.

In addition to assessing species' abundances on plates for comparison to Boyd's (1972) data, we also surveyed the adult community on the vertical sides of floating docks (the most abundant hard substratum available) to determine contemporary composition of the most mature fouling assemblages in Bodega Harbor. We quantified percent cover in five $0.0625 \mathrm{~m}^{2}$ quadrats at 4 locations that differ in distance from the shore. Quadrats were randomly placed just below the water surface, and a total of $N=100$ quadrats was counted over 5 surveys conducted in October 2006, June 2007, September 2007, August 2008, and July 2009. For each species, we calculated average total cover, live cover (relative proportion of occupied space, excluding bare space), and primary cover (live cover after excluding mussels which themselves function as substratum).

Recruitment. Recruitment of epibenthic species in Bodega Harbor was recorded between May 2005 and September 2009 (see supplementary Fig. S3 for sampling dates). To quantify recruitment, we deployed 4 sanded $10 \times 10 \mathrm{~cm}$ PVC plastic plates on a rack at a depth of $1 \mathrm{~m}$, as described above for the adult plates. At the end of each collection interval (1 to $4 \mathrm{wk}_{\text {; }}$ see supplementary Table S1), plates containing recruits were removed and transported to the lab where we counted and identified individuals to the lowest possible taxonomic level under a dissecting microscope. We replaced the collected recruitment plates with a new set of clean (washed in freshwater) and re-sanded plates. We calculated the average proportion of recruits that were non-native species from counts of individual recruits (as individuals per $100 \mathrm{~cm}^{2}$, or each $10 \times 10 \mathrm{~cm}$ plate) for our contemporary data (from the most continuous period of 2006-2007) and for Boyd's (1972) historical data on recruitment (measured over 4 wk intervals; Table 4 in Boyd 1972).

Environmental parameters. Temperature was measured using iButton (2005; Maxim Integrated Products) and TidbiT (2006-09; Onset Computer Corporation) temperature loggers deployed on racks adjacent to the recruitment plates at $1 \mathrm{~m}$ water depth. Temperature was recorded every 5 to $30 \mathrm{~min}$, and these measurements were used to calculate daily averages. Water chemistry (salinity and in vivo chlorophyll (chl) $a_{\text {, }}$ which is an indicator of phytoplankton food supply) was quantified for 3 water samples collected from a depth of $\sim 1 \mathrm{~m}$ using a sampling pole. Water samples were collected within $1 \mathrm{~h}$ of high tide to minimize variation associated with the tidal cycle. A refractometer was used to determine salinity, and chl a was measured with a handheld fluorometer (Aquafluor handheld fluorometer no. 8000-001, Turner Designs). Mean salinity and chl a values for each sampling date are averages of the 3 replicate water samples. Water sampling was conducted approx. twice weekly in 2006 and weekly in 2007-2009.

Recent temperatures in Bodega Harbor were compared to historical seasonal averages (Table 2 in Boyd 1972). In addition, we used finer-scale time-series data from a single dataset on ocean temperature at Bodega Marine Lab (a shoreline station on the outer coast) to calculate monthly averages for the periods of Boyd's (1972) study and our study (Bodega Ocean Observing Node, www.bml.ucdavis.edu/boon/; Scripps Institution of Oceanography 1960-1995). To examine the relationship between temperatures in Bodega Harbor (where surface heating would likely lead to higher temperatures) and the outer coast, we ran a linear regression on the daily averages from 2 full years (March 2006-March 2008) in which temperatures at the 2 locations were measured concurrently. Both the Bodega Harbor and outer coast temperature datasets were continuous over this period with few breaks (data were missing for a total of 32 days over these $2 \mathrm{yr}$ ).

Models of recruitment and environmental parameters. To determine the relationship between our con- 
temporary measurements of recruitment and environmental variation, we used structural equation modeling (SEM; see Grace 2006) to assess 4 models containing 1 to 3 environmental parameters. Each data point represented the cumulative recruitment over a single deployment interval, and we related recruitment to the mean value of environmental parameters (i.e. salinity, chl $a$, and temperature) measured during that interval. For each species and interval, we averaged the number of individuals on the 4 plates and calculated the number of recruits per plate per day. We calculated the mean temperature over the recruitment interval by averaging the daily mean temperatures for that period. Salinity and chl a values were the averages of values collected on sampling dates within the recruitment interval.

The 4 models (T, CT, ST, and CST; Fig. 1) included different combinations of environmental parameters. Temperature, as our variable of interest, was included in all 4 models. The models CT and ST included chl a and salinity respectively, and the model CST included all 3 environmental factors. Models incorporating $>1$ of the environmental parameters also included errors that were allowed to covary freely between the parameters (note that collinearity was low, with $\mathrm{R}^{2}$ values of 0.05 and 0.12 for correlations of temperature with salinity and chl a respectively, and $\mathrm{R}^{2}<0.001$ for salinity vs. chl a).

Day length was the single exogenous variable in all 4 models and was used as an indicator of the time of year (i.e. season) and light intensity, which has been associated with spawning for several of these species (Svane \& Young 1989, Wendt 2000, Stachowicz et al. 2002, Marshall \& Keough 2004). Day length was, thus, hypothesized to be related to recruitment both directly (e.g. via effects of light intensity) and indirectly, due to effects on environmental variables (e.g. seasonality of upwelling leading to temperature variation). Thus, in addition to accounting for autocorrelation between sampling intervals, explicitly including day length in our analysis allowed us to address the relationship between intra-annual variation in both temperature and recruitment after accounting for seasonal changes.

We evaluated recruitment as a function of the environmental variables for intervals over which data were measured concurrently ( $N=80$ for the temperature model $\mathrm{T}$, and $N=36$ for models also including chl $a$ and/or salinity). We ran all 4 alternate SEM models separately for each of the 15 species that settled on our recruitment plates between May 2005 and September 2009, as well as for all natives, all non-natives, and total recruitment, using the statistical software $\mathrm{R}(\mathrm{R}$ Core Development Team 2008) with the 'sem' and 'sem.additions' packages. Chl a values were square-
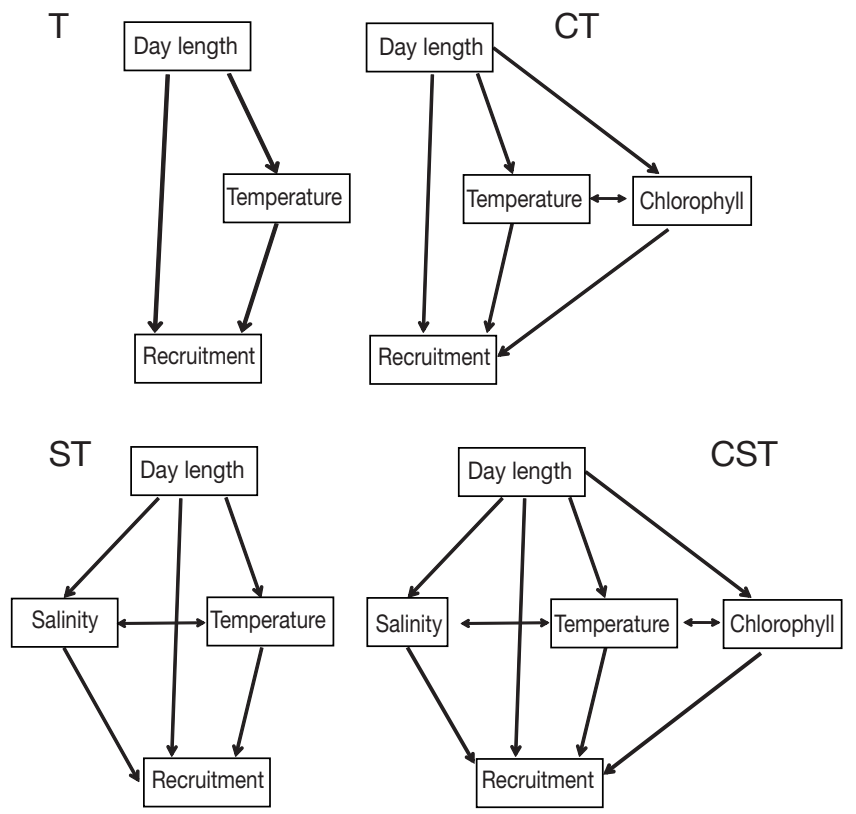

Fig. 1. Structural equation models $(\mathrm{T}, \mathrm{CT}, \mathrm{ST}$, and CST) of the relationship between environmental parameters and recruitment. All 4 models included temperature (our primary variable of interest) and day length (which accounted for seasonality in recruitment)

root transformed, and recruitment rates for each species were either square-root or power $\left(y^{0.1}\right)$ transformed. When necessary, we applied the SatorraBentler correction to our coefficient estimates to correct for a lack of multivariate normality. For comparison with the SEM results, we also ran multiple regression analyses for recruitment ( $N=33$ intervals) as a function of all 3 environmental parameters, as well as of day length and recruitment in the previous interval (to account for any autocorrelation; Durbin-Watson statistic $=1.70$ to $2.69, \mathrm{p}>0.07$ ).

\section{RESULTS}

\section{Changes in community composition between time periods}

The native vs. non-native composition of the Bodega Harbor epibenthic community has changed over the past 35 yr due to both recent species introductions and alterations in the abundances of already present species (Table 1). Native species dominated the 1970 plates whereas non-native species dominated the 2006 plates and dock surfaces (Fig. 2). On plates, non-native species cover was an order of magnitude higher in 2006 than in $1970(\geq 60 \%$ vs. $\leq 6 \%$ ) whereas the cover of natives decreased from $\geq 85 \%$ in 1970 to $\leq 39 \%$ in 2006 
Table 1. Species commonly observed in the Bodega Harbor epibenthic community in 1969-1971 (Boyd 1972) and/or in 2005-2009 (this study). Origin classifications - N: native, I: introduced, i.e. non-native, and C: cryptogenic. Abundance categories - 0: absent, X: present in low abundance, and XX: common; $\mathrm{u}$ : non-identified species that could have been present. The 8 most common (XX) species in 1969-1971 were those that Boyd (1972) referred to as dominant and in 2005-2009 were those that represented $>3 \%$ cover in surveys of the docks and/or experimental plates. Note that additional species that were rarely observed were reported by Boyd (1972)

\begin{tabular}{|c|c|c|c|c|c|}
\hline Taxon & Origin & Species & $1969-1971$ & $05-2009$ & Change \\
\hline \multirow[t]{6}{*}{ Bryozoans } & I & Bowerbankia gracilis & $\mathrm{XX}$ & $\mathrm{X}$ & - \\
\hline & I & Bugula neritina & $\mathrm{X}$ & $\mathrm{XX}$ & + \\
\hline & I & Cryptosula pallasiana & $\mathrm{XX}$ & $\mathrm{u}$ & ? \\
\hline & I & Schizoporella sp. & $\mathrm{XX}$ & $\mathrm{XX}$ & \\
\hline & I & Watersipora subtorquata ${ }^{a}$ & 0 & $\mathrm{XX}$ & + \\
\hline & $\mathrm{N}$ & Bugula californica & $\mathrm{XX}$ & $\mathrm{X}$ & - \\
\hline \multirow[t]{9}{*}{ Tunicates } & I & Botrylloides violaceus & $\mathrm{u}$ & $\mathrm{XX}$ & + \\
\hline & I & Botryllus schlosseri & $\mathrm{X}$ & $\mathrm{X}$ & \\
\hline & I & Diplosoma listerianum ${ }^{\mathrm{b}}$ & $\mathrm{X}$ & $\mathrm{XX}$ & + \\
\hline & I & Didemnum vexillum $^{\mathrm{c}}$ & 0 & $\mathrm{XX}$ & + \\
\hline & $\mathrm{N}$ & Ascidia ceratodes & $\mathrm{XX}$ & $\mathrm{XX}$ & \\
\hline & $\mathrm{N}$ & Distaplia occidentalis & 0 & $\mathrm{X}$ & + \\
\hline & $\mathrm{C}$ & Botrylloides sp. ${ }^{\mathrm{d}}$ & $\mathrm{XX}$ & $\mathrm{u}$ & $?$ \\
\hline & $\mathrm{C}$ & Botrylloides diegensis & $\mathrm{u}$ & $\mathrm{X}$ & $?$ \\
\hline & $\mathrm{C}$ & Ciona sp. & 0 & $\mathrm{X}$ & + \\
\hline Anemones & $\mathrm{S} \mathrm{N}$ & Metridium senile & $\mathrm{X}$ & $\mathrm{XX}$ & + \\
\hline Annelids & $\mathrm{N}$ & Spirorbis sp. & $\mathrm{X}$ & $\mathrm{X}$ & \\
\hline Barnacles & $\mathrm{N}$ & Balanus sp. (crenatus?) & $\mathrm{XX}$ & $\mathrm{X}$ & - \\
\hline Hydroids & $\mathrm{C}$ & Obelia spp. & $\mathrm{XX}$ & $\mathrm{X}$ & - \\
\hline Sponges & $\mathrm{C}$ & Unknown & $\mathrm{X}$ & $\mathrm{X}$ & \\
\hline
\end{tabular}

(Fig. 2). One-sample $t$-tests showed that non-native species composed a higher proportion of space on plates deployed both in May $(t=12.847$, df $=6$, p < $0.001)$ and in July of $2006(t=7.227, \mathrm{df}=7, \mathrm{p}<0.001)$ as compared to Boyd's (1972) plate data.

The common species in the community also changed. Boyd (1972) reported that the 8 most common species on plates included 3 non-natives, 3 natives, and 2 cryptogenic species. Of the 8 most common species on the May and July plates in 2006-2007, 6 were non-native, with the tunicate Ascidia ceratodes being the only common native. The native bryozoan Bugula californica and the barnacle Balanus crenatus, which were formerly among the 8 most common species in the community, were not present on May and July 2006 plates (but were found in low abundance on the docks and on recruitment plates; Table 1) despite covering as high as 5 and $59 \%$ on 1970 plates respectively (Boyd 1972). Of the 6 non-natives that were most common on the 2006 plates, all but one (the bryozoan Schizoporella sp.) were rare or absent in 1969-1971, including the bryozoans Bugula neritina and Watersipora subtorquata and the tunicates Botrylloides violaceus, Diplosoma listerianum, and Didemnum vexillum. On average, the 8 most common species on the 2006 plates represented $>75 \%$ of primary live cover on the docks, and we address their recruitment patterns in more detail below. In total, we identified 13 species on the adult plates, including 3 natives, 8 non-natives, and 2 cryptogenic species.

In the adjacent dock community, non-native species also currently represent the majority of species and of cover (Fig. 2). The 8 most common species in the dock community included 3 natives (Ascidia ceratodes, Balanus crenatus, and the anemone Metridium senile) and 5 non-native species: the mussel Mytilus galloprovincialis (28.5\% live cover), Watersipora subtorquata $(22.4 \%)$, Botrylloides violaceus (9.4\%), Diplosoma listerianum (5.5\%), and Bugula neritina (2.8\%). Surveys conducted between 2005 and 2009 revealed that non-natives represented $70.5 \%$ of cover and $85.2 \%$ of live cover; bare space averaged $11.9 \%$.

\section{Shifts in the recruitment phenology of native vs. non-native species}

The relative timing of native and non-native recruitment appeared to have shifted between 1969-1971 and 2006-2007 (Fig. 3). In 1969-1971, native recruits generally exceeded or equaled non-native recruits in spring and early summer, with non-natives having a numerical advantage in mid-summer through fall (Fig. 3A). In contrast, non-native recruits exceeded native recruits in the spring (April to June) in 2006 and 2007, whereas natives usually had an advantage in summer and fall (Fig. 3B). Because variation between individual plates was not reported by Boyd (1972), our ability to compare these patterns statistically is limited to treating individual years as replicates. Despite very low power, comparisons by month between time periods showed that non-natives recruited in significantly higher numbers in 2006-2007 than in 1969-1970 for 2 mo-June $(t=4.993, \mathrm{df}=2, \mathrm{p}=0.038)$ and December $(t=6.802, \mathrm{df}=2, \mathrm{p}=0.021)-$ while natives tended to recruit in greater numbers during the late summer and early fall (although for these months, $\mathrm{p}>0.08$ ). 

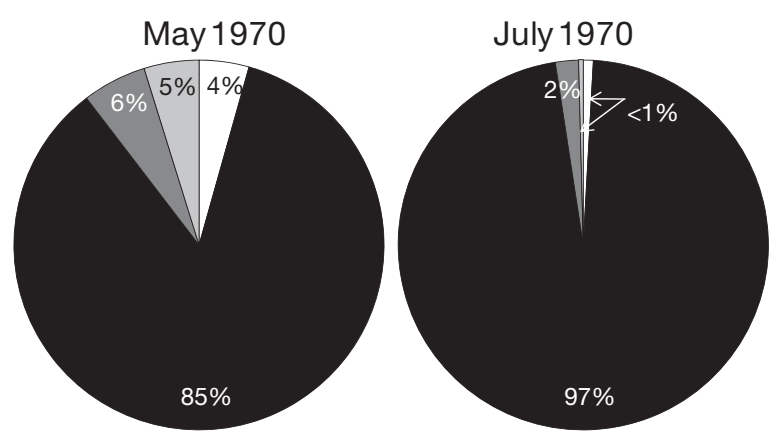

May 2006
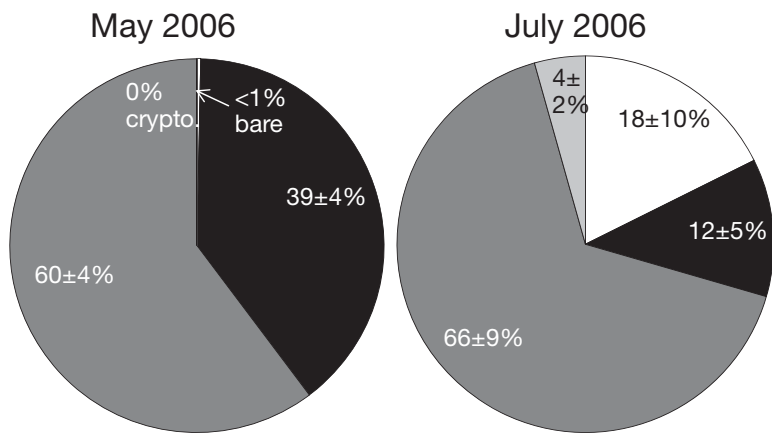

Dock surveys (2005-2009)
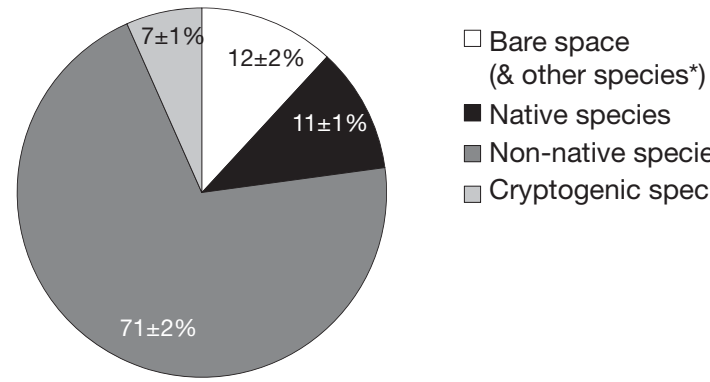

- Native species

$\square$ Non-native species

$\square$ Cryptogenic species

Fig. 2. Historical and contemporary composition of the Bodega Harbor epibenthic community. Plates were deployed in May and July 1970 and 2006 and were surveyed the following winter, in early March (1971) or mid-February (2007), respectively. Contemporary values are given as means \pm SE of $N=7$ plates deployed in May 2006, $N=8$ plates deployed in July 2006, and $N=100$ quadrats counted during 5 dock surveys; errors for Boyd's data are not available (Table 12 in Boyd 1972). * For 1970 plates, white represents both bare space and 'other species', i.e. those in Boyd (1972) that were not identified to species level

\section{Changes in environmental parameters between time periods}

Local seawater temperature has increased concurrently with the shifts in the epibenthic community composition of Bodega Harbor. The current harbor temperature is $\sim 1^{\circ} \mathrm{C}$ higher than it was when Boyd (1972) studied the local community (Fig. 4). Note that neither study was conducted during a strong El NiñoSouthern Oscillation (ENSO) anomaly (Wolter 2010).

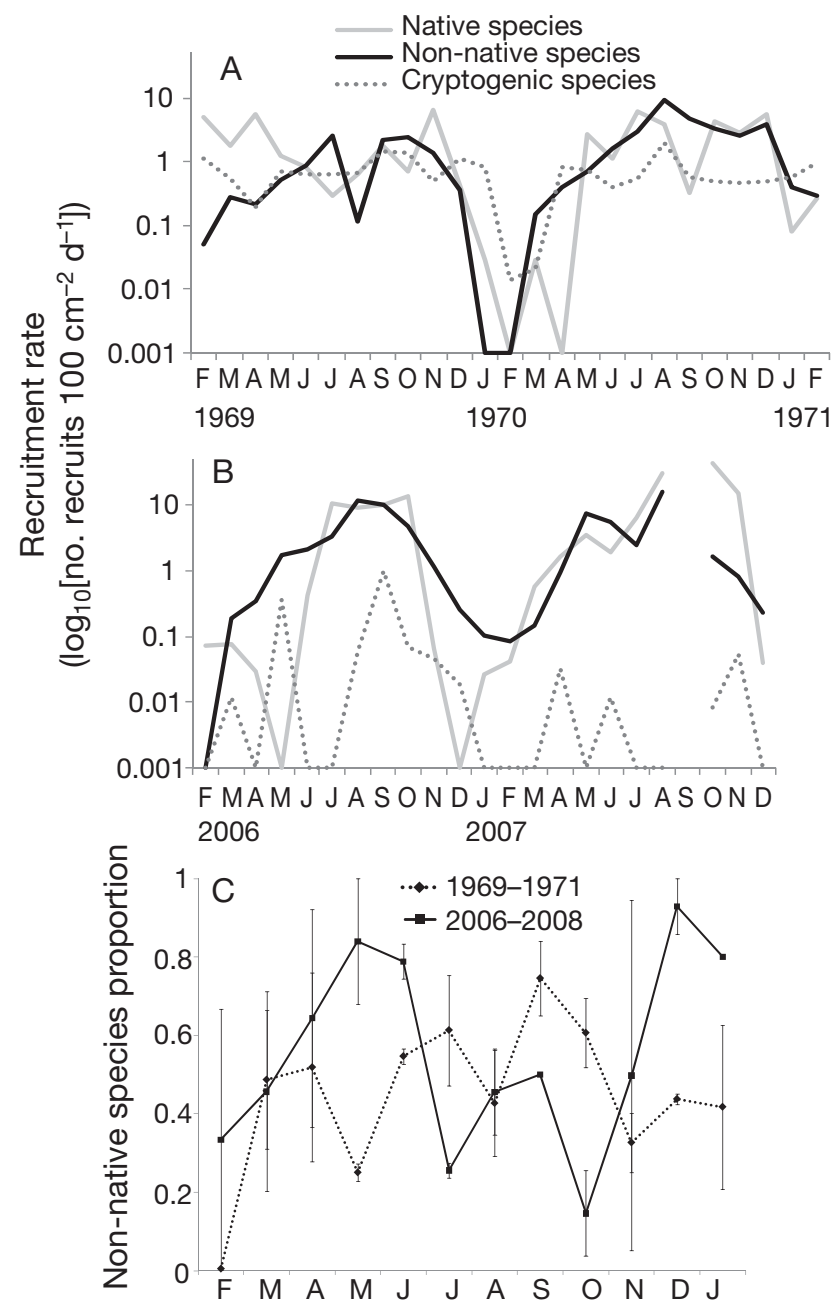

Fig. 3. Recruitment rates $\left(\log _{10}\left[\right.\right.$ no. recruits $100 \mathrm{~cm}^{-2}$ plate $\left.\left.\mathrm{d}^{-1}\right]\right)$ averaged by month during (A) a historical (1969-1971) and (B) a recent (2006-2007) 2 yr sampling interval and summarized as $(\mathrm{C})$ proportions of new individual recruits that were non-native species over the 2 sampling intervals. In panels (A) and (B), total number of recruits of native, non-native, and cryptogenic species were calculated from recruitment rates reported in Boyd (1972; average of $N=5$ plates measured over $4 \mathrm{wk}$ intervals) and in this study ( $N=4$ plates, values are averages of 1 to 4 recruitment intervals $\mathrm{mo}^{-1}$ ). Note that zero values were plotted as 0.001 , and no data were available for September 2007. For panel (C), we calculated the proportion of recruits comprised of non-native species (no. nonnative ind./total non-native and native ind. $100 \mathrm{~cm}^{-2}$ ). Monthly values are averages of $2 \mathrm{yr}$ of data $( \pm \mathrm{SE}$, except for missing data in Sep 2007 and Jan 2008). Cryptogenic species (those not identifiable as native or non-native) were not included in the analyses of proportions

The average temperature was $11.8^{\circ} \mathrm{C}$ in 1970 (Boyd 1972 ), and we measured a daily average temperature of $13.0^{\circ} \mathrm{C}$ based on continuous records collected between March 2006 and March 2008. This increase in local temperature was also apparent based on continuous temperature records from the outer coast site 
(Bodega Ocean Observing Node, www.bml. ucdavis.edu/boon/; E. Sanford unpubl. data), and coastal temperatures are strongly related to those inside Bodega Harbor $\left(\mathrm{R}^{2}=0.45\right.$, $\mathrm{p}<0.0001)$. Salinity in Bodega Harbor also appeared to have increased between the 2 time points, with typical values ranging from 32 to 34 during Boyd's (1972) study and averaging $35.9( \pm 0.2 \mathrm{SE})$ during our study (see also Sorte 2010).

\section{Correlation between environmental parameters and recruitment}

In 2005-2009, water temperatures in Bodega Harbor varied seasonally, peaking during the primary recruitment season (April through August), and inter-annually, with 2006 being the warmest year (mean $\pm \mathrm{SE}$ : $14.77 \pm 0.12^{\circ} \mathrm{C}$ during the recruitment season) and 2007 being the coolest $\left(13.64 \pm 0.11^{\circ} \mathrm{C}\right.$ during the recruitment season; Fig. 4B). Water temperatures ranged from a minimum daily average of $8.02^{\circ} \mathrm{C}$ in January 2007 to a maximum of $18.94^{\circ} \mathrm{C}$ during a heat wave in July 2006 when average daily temperature remained $>18^{\circ} \mathrm{C}$ for 6 continuous days.

The rate of recruitment into the epibenthic community was positively related to daily average temperature (in SEM, multiple regression, or both analyses) for 11 of 15 species that settled on our recruitment plates between May 2005 and September 2009, including 2 of 5 natives and all 8 non-natives (Table 2). In all 4 SEM and the multiple regression models, total non-native recruitment increased with increasing temperature $(p<0.03)$, whereas recruitment rate of native species did not change with temperature based on the 4 models that included multiple environmental variables $(p>0.24$ for all except the T-model; Table 2). After using multiple regression to account for the effects of day length, chl $a$, salinity, and recruitment in the previous time interval, there was still a significant positive correlation between the residuals of total recruitment and temperature for non-native species $(p=0.018)$, but not for native species ( $p=0.213$; Fig. 5). Non-temperature environmental variables were only rarely correlated with recruitment of individual species and with total native or non-native recruitment as follows: chl a was positively related to recruitment for Didemnum vexillum (chl a p $<0.001$ for both the multiple regression and SEM coefficients), whereas salinity was negatively related to recruitment for Distaplia occidentalis (multiple regression $\mathrm{p}=0.043$; SEM coefficient $\mathrm{p}=0.021$ )

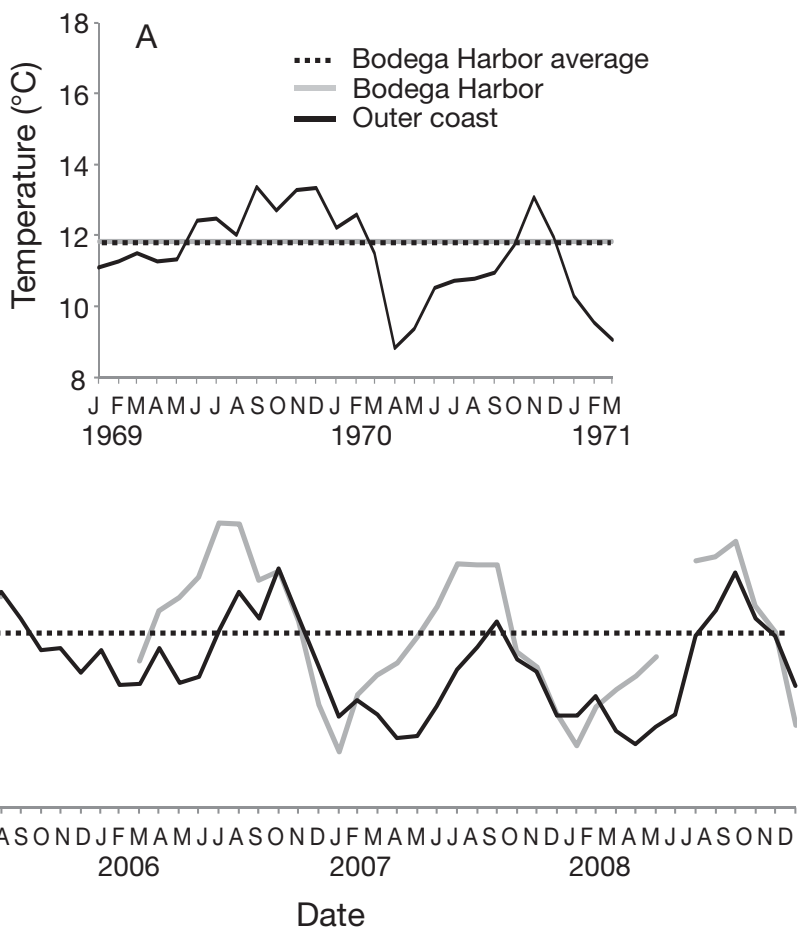

Fig. 4. Local seawater temperatures during (A) 1969-1971 and (B) 2005Average Bodega Harbor temperature in 1969-1971 $\left(11.8^{\circ} \mathrm{C}\right.$, dotted (grey line in B) by dataloggers deployed at $1 \mathrm{~m}$ depth; the average ast values (black line) are monthly averages of temperatures measured daily at Bodega Marine Laboratory (see 'Materials and Methods')

and native species overall (multiple regression $\mathrm{p}=$ 0.043; SEM coefficient $\mathrm{p}=0.033$ ).

Recruitment of common epibenthic species varied greatly both during the recruitment season and between years (Fig. 6). Initiation of recruitment tended to occur in April for the non-native tunicates and later (May, or even July for Bugula neritina) for non-native bryozoans. Recruitment timing and magnitude were highly idiosyncratic for the 2 most commonly recruiting native species (Distaplia occidentalis, Bugula californica; Fig. 6). As compared to recruitment dynamics in the coolest year (2007), recruitment in the warmest year (2006) tended to occur earlier and at greater rates for 5 of 6 non-natives and for the native Bugula californica. However, for the native Distaplia occidentalis and the non-native Diplosoma listerianum, recruitment occurred later and at lower rates in 2006, but earlier and at higher rates in 2007 .

\section{DISCUSSION}

Our comparison of historical and contemporary records indicates a change in the species composition of 


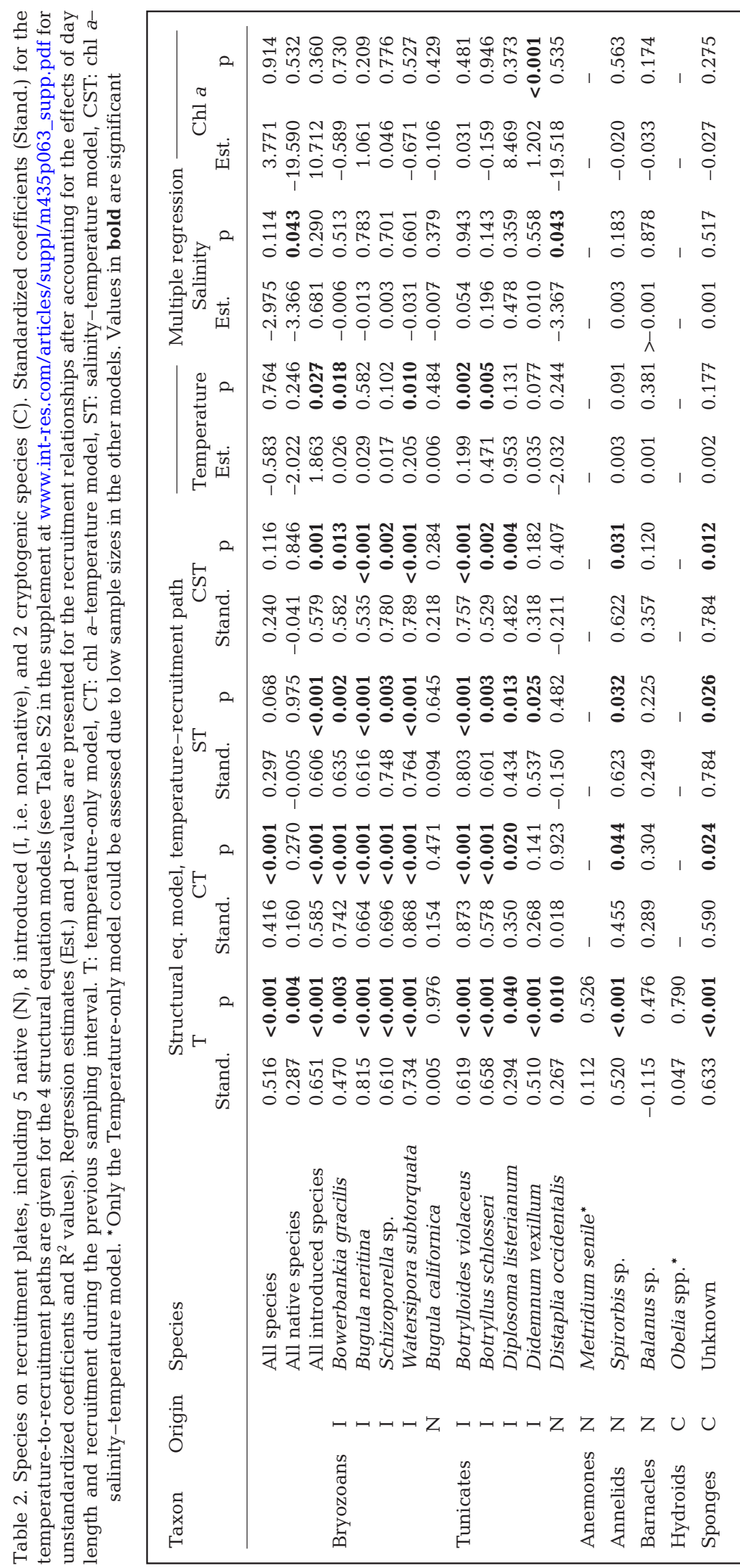

the Bodega Harbor epibenthic community over the past $\sim 35$ yr to one that is increasingly dominated by non-native species. New introductions certainly played a role in this compositional shift, as many of the most common species - including Watersipora subtorquata, which now covers $>20 \%$ of the floating docks - were not present during Boyd's (1972) study. Our data are also consistent with the hypothesis that the establishment and success (i.e. increase in abundance) of non-native species has been enhanced by their more favorable response to increased temperature relative to natives. We document an increase in mean annual seawater temperature of $\sim 1.0^{\circ} \mathrm{C}$ (Fig. 4), which is similar to the warming associated with an increase in abundance of southern-distributed species, and a decrease of northerndistributed species, in a central California intertidal community (Barry et al. 1995, Sagarin et al. 1999). In our study, recruitment increased at warmer temperatures for all 8 non-natives, individually and in total, whereas recruitment was not related to temperature for 3 of 5 native species as well as for total native recruits.

In addition to the increased magnitude of recruitment, non-native species recruited earlier at increased ocean temperatures (Figs. $3 \& 6$ ). This mechanism may be quite common given similar findings across locations that vary in mean temperature and seasonality (e.g. Keough \& Chernoff 1987, Stachowicz et al. 2002, Auker \& Oviatt 2008), especially despite the potential for geographic variation in population responses to temperature (Grosholz 2001, Yund \& Stires 2002). Thus, the effects of changing temperature on the timing of recruitment, combined with widespread evidence for priority effects among sessile organisms (Sutherland 1974, 1978, D'Antonio et al. 2001), suggest a clear mechanism by which rising temperatures could lead to non-native dominance in Bodega Harbor and similar communities.

An even better understanding of the relationship between temperature and recruitment requires further studies of the links between recruitment rates and adult abundances (including time lags, dispersal distances, and larval sources), which 


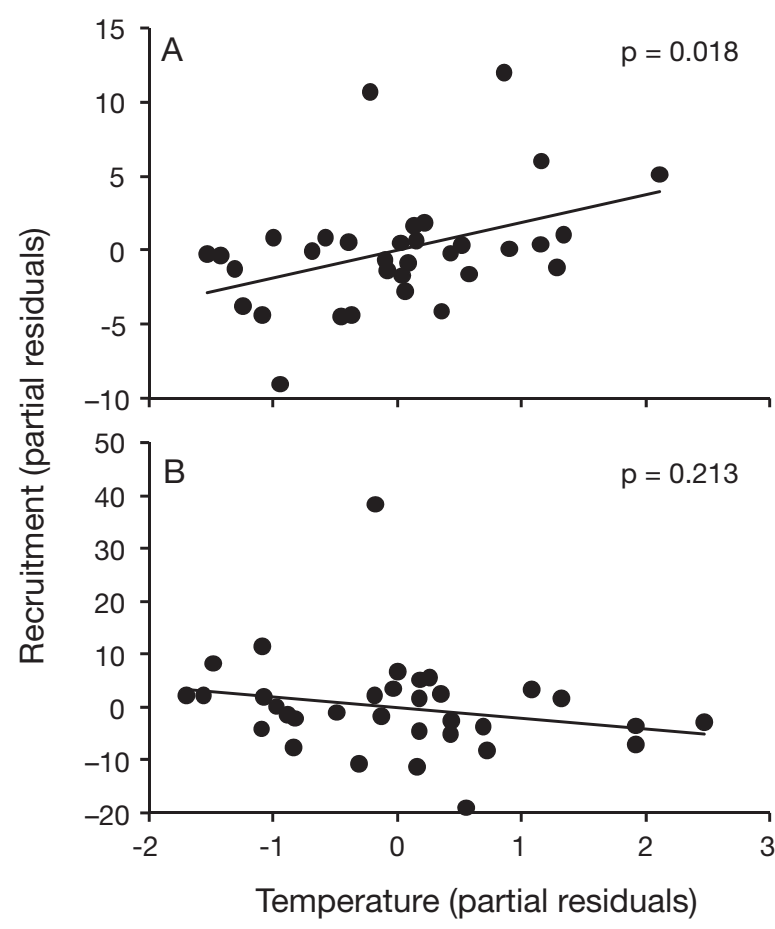

Fig. 5. Temperature effects on the recruitment of (A) nonnative and (B) native species in the epibenthic community of Bodega Harbor. Partial residual plots illustrate relationships between temperature and recruitment after accounting for the effects of day length, chl $a$, salinity, and recruitment during the previous interval. Recruitment of non-native species increased with increasing temperature $(p=0.018)$, but there was no relationship between recruitment of native species and temperature $(p=0.213)$

often constitute a 'black box' in this and other systems. Temperature can affect recruitment through direct effects on adult fecundity (Yund \& Stires 2002), larval development (Berrill 1935, Scheltema \& Williams 1982), spawning (Davis 1989), and/or larval survival (Scheltema \& Williams 1982), but we have no evidence to assess which of these underlie the temperaturerecruitment link we observed. Additionally, due to scaling of reproductive output with body size, a positive relationship of temperature with other demographic rates (i.e. growth and survival; Sorte et al. 2010a,b, Zerebecki \& Sorte 2011) could feed back to increase fecundity and recruitment.

Despite these known mechanistic links between temperature and reproduction in the types of epibenthic organisms we studied, most natives did not respond to increased temperature. This could be because annual temperature variation is generally low in places where native hard substrate communities would develop in northern California (Sorte et al. 2011, Zerebecki \& Sorte 2011). Furthermore, high temperature is not necessarily indicative of favorable conditions for reproduction, as high food availability is associated with low temperatures caused by upwelling on the
California coast (e.g. Blanchette et al. 2006). Thus, there may have historically been little selective pressure to reproduce during warm periods. In addition, if temperature indeed caused increases in native reproduction, then these effects might have been overwhelmed by non-natives responding more strongly to high temperatures and reducing native reproductive output due to competition. Non-native species in our communities, in contrast, may respond positively to ocean warming because many of them are from warmer biogeographic provinces or regions with greater seasonality and in which temperature is a more reliable cue of favorable conditions for reproduction (see Cohen 2005, Zerebecki \& Sorte 2011).

Although many species treated here display consistent responses to warmer temperatures, such responses do not seem to explain the increase in all species. For example, the widespread native tunicate Distaplia occidentalis has shown decreased recruitment and survival (Sorte et al. 2010b) at elevated temperatures, yet it is common today despite being absent from Boyd's (1972) surveys. Such inconsistencies indicate that other forces may also contribute to compositional shifts. For example, competitive superiority of recently established invaders likely played an important role in the observed compositional shift. The 2 recent invaders Watersipora subtorquata and Didemnum vexillum are competitively dominant over several other colonial species (Edwards \& Stachowicz 2010) and could be partly responsible for reduced native cover in recent years. A native that has remained abundant, Ascidia ceratodes, is a dominant competitor even to invaders like W. subtorquata (Edwards \& Stachowicz 2011), which may have contributed to its persistence in the community.

Changes in other abiotic factors such as salinity, food availability, disturbance, and pollution could also have influenced the observed community shift; however, evidence for these factors' roles is weak. Our data for salinity showed a modest increase between sampling periods. High salinity was associated with a decrease in the recruitment of the native Distaplia occidentalis; however, this species actually increased in abundance between 1970 and the present. Similarly, chl $a$, which is an index of food availability, was only associated with recruitment for one species (Didemnum vexillum), but chlorophyll levels associated with recent increases in upwelling (Bakun 1990, Snyder et al. 2003) could have also influenced species in other ways (e.g. by increasing growth rate and competitive ability of nonnatives). Increases in pollution (Piola \& Johnston 2007) or decreases in predators (Sutherland 1974, Karlson 1978, Nydam \& Stachowicz 2007, Osman \& Whitlatch 2007) are both known to influence the relative abundance of natives and non-natives in fouling communi- 
Non-native tunicates

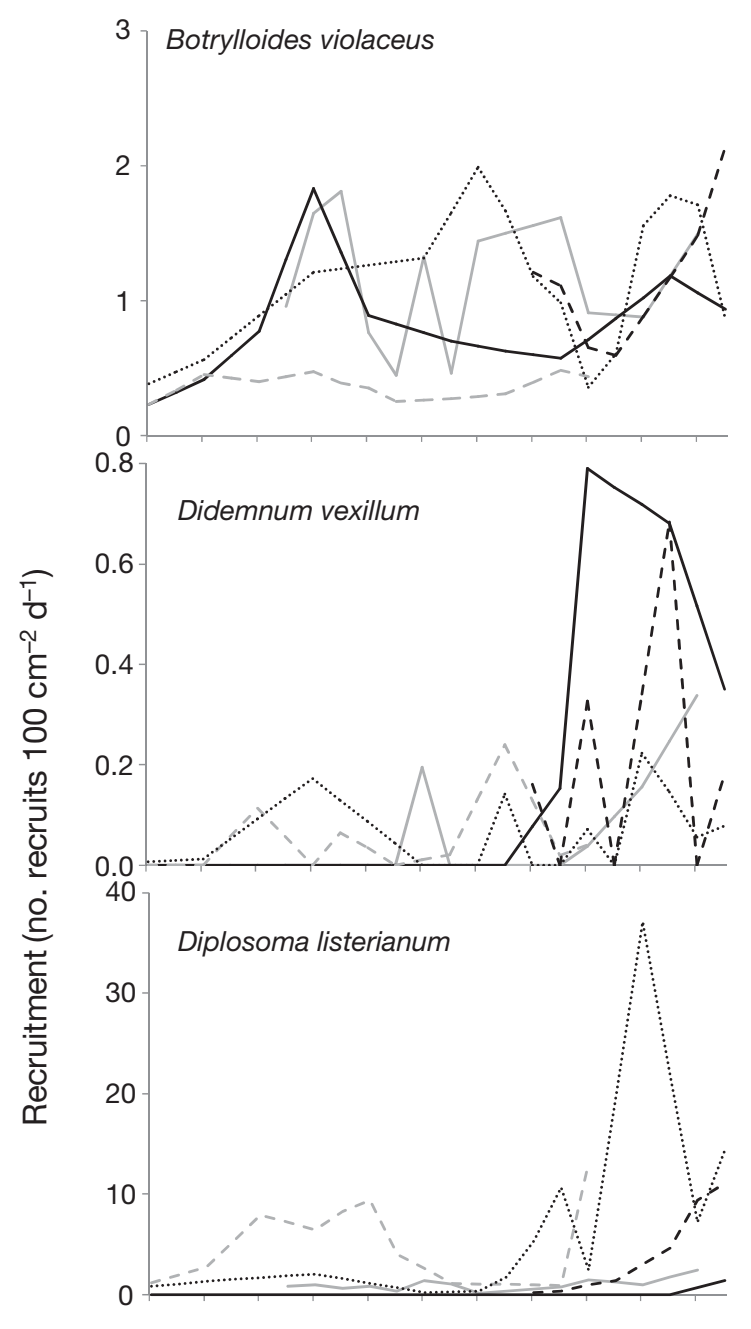

Native tunicate

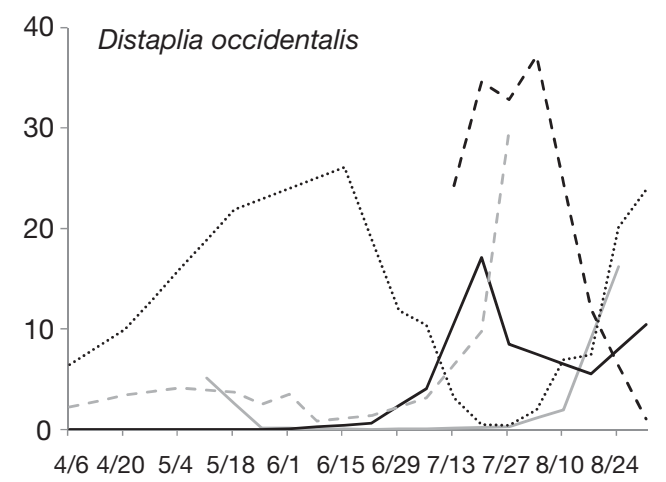

Non-native bryozoans
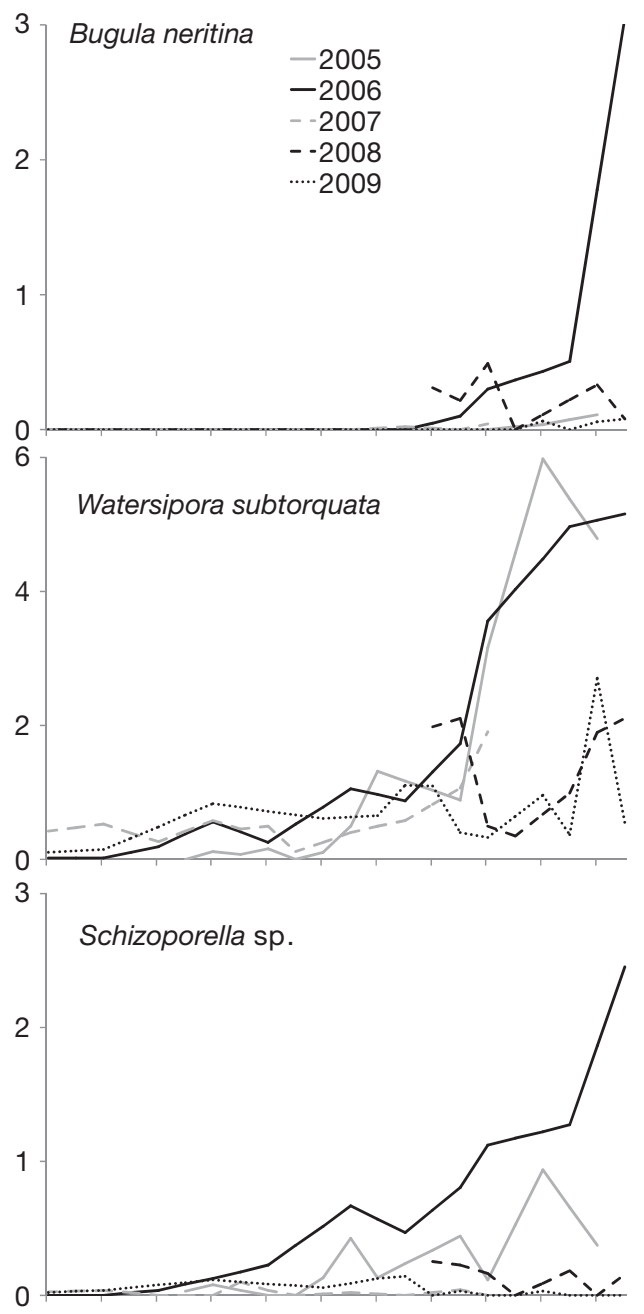

Native bryozoan

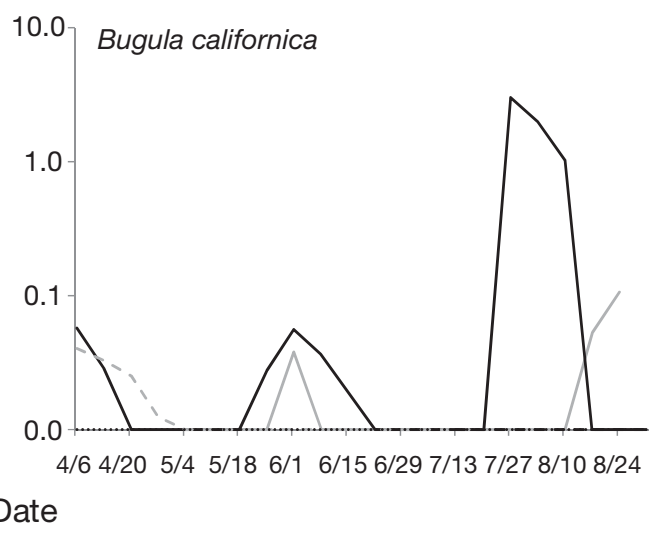

Fig. 6. Epibenthic species recruitment measured in Bodega Harbor during the peak recruitment season (Apr to Aug, date given as $\mathrm{mo} / \mathrm{d}$ ) of 2005-2009. Values are recruits per day averaged from four $100 \mathrm{~cm}^{2}$ settling plates over a known recruitment interval (see Table S1 in the supplement at www.int-res.com/articles/suppl/m435p063_supp.pdf), and recruitment rates are interpolated between samplings to create a smoothed line. Missing data are as follows: April 2005, August 2007, and April to June 2008.

Note that the scales of the $y$-axes vary between species, and recruitment of Bugula californica is plotted on a log scale 
ties. However, we lack data to assess whether there has been a directional change in either of these factors that could explain the observed shifts.

In conclusion, we have documented an increase in non-native dominance in the Bodega Harbor epibenthic community over the past $\sim 35 \mathrm{yr}$, concurrent with an increase in local ocean temperatures. Given that higher temperatures enhanced the overall recruitment of non-native species but not of native species, changes in recruitment with ocean warming could help to maintain the observed compositional shift by increasing the success of non-native species in this system. The competitive superiority of species that have recently been introduced to the Harbor via human activities also likely plays an important role, and this superiority may, itself, be influenced by changes in temperature. These observational data extending decades into the past, together with recent experimental data on shorter time scales (Sorte et al. 2010b), lead to predictions of continued increases in non-native dominance with future warming. Finally, the links between climate, phenology, and subsequent community interactions (also see Stachowicz et al. 2002, Willis et al. 2010) may represent a general mechanism of warming-induced shifts in community composition in a wide range of the earth's ecosystems.

Acknowledgements. We especially thank M. Bracken for assistance at all stages of this project. The long-term datasets would not have been possible without the help of J. Abbott, A. Chaudoin, R. C. Coates, E. Jones, M. Nydam, P. Reynolds, and K. Sellheim. We also thank J. Byrnes, A. Carranza, R. C. Coates, K. Edwards, B. Huckleberry, and S. Williams for suggestions and assistance; J. Byrnes, M. Doellman, S. Kent, L. Miller, E. Sanford, and S. Williams for comments that greatly improved the manuscript; and the staff at Spud Point Marina for their assistance and for access to our field site. Funding was provided to C.J.B.S. by an AAUW American Fellowship, and a CEQI Fellowship from the California Ocean Protection Council, as well as by the National Science Foundation (DGE-0114432 for the UC-Davis Biological Invasions IGERT Program). This publication is a contribution of the Bodega Marine Laboratory, University of California at Davis.

\section{LITERATURE CITED}

Auker LA, Oviatt CA (2008) Factors influencing the recruitment and abundance of Didemnum in Narragansett Bay, Rhode Island. ICES J Mar Sci 65:765-769

Bakun A (1990) Global climate change and intensification of coastal ocean upwelling. Science 247:198-201

Barry JP, Baxter CH, Sagarin RD, Gilman SE (1995) Climaterelated, long-term faunal changes in a California rocky intertidal community. Science 267:672-675

Berrill NJ (1935) Studies in tunicate development. Part III. Differential retardation and acceleration. Philos Trans R Soc Lond B 225:255-326

Blanchette CA, Broitman BR, Gaines SD (2006) Intertidal community structure and oceanographic patterns around Santa Cruz Island, CA, USA. Mar Biol 149:689-701
Boyd MJ (1972) Fouling community structure and development in Bodega Harbor, California. PhD thesis, University of California, Berkeley

Byrnes J, Stachowicz JJ (2009) Short and long term consequences of increases in exotic species richness on water filtration by marine invertebrates. Ecol Lett 12:830-841

Chown SL, Slabber S, McGeoch MA, Janion C, Leinaas HP (2007) Phenotypic plasticity mediates climate change responses among invasive and indigenous arthropods. Proc Biol Sci 274:2531-2537

Cohen AN (2005) Guide to the exotic species of San Francisco Bay. San Francisco Estuary Institute, Oakland, CA, www.exoticsguide.org

Cohen AN, Carlton JT (1995) Nonindigenous aquatic species in a United States estuary: a case study of the biological invasions of the San Francisco Bay and delta. US Fish and Wildlife Service, Washington, DC

Cohen AN, Carlton JT (1998) Accelerating invasion rate in a highly invaded estuary. Science 279:555-558

D'Antonio CM, Flint Hughes R, Vitousek PM (2001) Factors influencing dynamics of two invasive $\mathrm{C} 4$ grasses in seasonally dry Hawaiian woodlands. Ecology 82:89-104

Davis AR (1989) Temperature correlates with the daily release of larvae and their settlement in a temperate Australian ascidian. In: Ryland JS, Tyler PA (eds) 23rd European Mar Biol Symp. Olsen and Olsen ApS, Fredensborg, p 61-65

Dean TA, Hurd LE (1980) Development in an estuarine fouling community: the influence of early colonists on later arrivals. Oecologia 46:295-301

> Dijkstra J, Harris LG, Westerman E (2007) Distribution and long-term temporal patterns of four invasive colonial ascidians in the Gulf of Maine. J Exp Mar Biol Ecol 342:61-68

Dukes JS, Mooney HA (1999) Does global change increase the success of biological invaders? Trends Ecol Evol 14: 135-139

Edwards KF, Stachowicz JJ (2010) Multivariate tradeoffs, succession, and phenological differentiation in a guild of colonial invertebrates. Ecology 91:3146-3152

Edwards KF, Stachowicz JJ (2011) Spatially stochastic settlement and the coexistence of benthic marine animals. Ecology 92:1094-1103

> Epelbaum A, Herborg LM, Therriault TW, Pearce CM (2009) Temperature and salinity effects on growth, survival, reproduction, and potential distribution of two non-indigenous botryllid ascidians in British Columbia. J Exp Mar Biol Ecol 369:43-52

Fields PA, Rudomin EL, Somero GN (2006) Temperature sensitivities of cytosolic malate dehydrogenases from native and invasive species of marine mussels (genus Mytilus): sequence-function linkages and correlations with biogeographic distribution. J Exp Biol 209:656-667

Grace JB (2006) Structural equation modeling and natural systems. Cambridge University Press, Cambridge

Grosholz E (2001) Small spatial-scale differentiation among populations of an introduced colonial invertebrate. Oecologia 129:58-64

> Harris L, Tyrrell M (2001) Changing community states in the Gulf of Maine: synergism between invaders, overfishing and climate change. Biol Invas 3:9-21

IPCC (2007a) Climate change 2007: the physical science basis. Cambridge University Press, Cambridge

IPCC (2007b) Climate change 2007: impacts, adaptation and vulnerability. Cambridge University Press, Cambridge

Karlson R (1978) Predation and space utilization patterns in a marine epifaunal community. J Exp Mar Biol Ecol 31: 225-239

Keough MJ, Chernoff H (1987) Dispersal and population variation in the bryozoan Bugula neritina. Ecology 68:199-210 
Knowlton N, Jackson JBC (2008) Shifting baselines, local impacts, and global change on coral reefs. PLoS Biol 6:e54

Lambert CC, Lambert G (1998) Non-indigenous ascidians in southern California harbors and marinas. Mar Biol 130: 675-688

Marshall DJ, Keough MJ (2004) Variable effects of larval size on post-metamorphic performance in the field. Mar Ecol Prog Ser 279:73-80

> McCarthy A, Osman RW, Whitlatch RB (2007) Effects of temperature on growth rates of colonial ascidians: a comparison of Didemnum sp. to Botryllus schlosseri and Botrylloides violaceus. J Exp Mar Biol Ecol 342:172-174

Nydam M, Stachowicz JJ (2007) Predator effects on fouling community development. Mar Ecol Prog Ser 337:93-101

Osman RW (1977) The establishment and development of a marine epifaunal community. Ecol Monogr 47:37-63

Osman RW, Whitlatch RB (2007) Variation in the ability of Didemnum sp. to invade established communities. J Exp Mar Biol Ecol 342:40-53

Piola RF, Johnston EL (2007) Pollution reduces native diversity and increases invader dominance in marine hardsubstrate communities. Diversity Distrib 14:329-342

R Core Development Team (2008) R: A language and environment for statistical computing. R Foundation for Statistical Computing, Vienna

Ruiz GM, Carlton JT, Grosholz ED, Hines AH (1997) Global invasions of marine and estuarine habitats by nonindigenous species: mechanisms, extent, and consequences. Am Zool 37:621-632

Sagarin RD, Barry JP, Gilman SE, Baxter CH (1999) Climaterelated change in an intertidal community over short and long time scales. Ecol Monogr 69:465-490

Sala OE, Stuart Chapin F III, Armesto JJ, Berlow E and others (2000) Global biodiversity scenarios for the year 2100. Science 287:1770-1774

Scheibling RE, Gagnon P (2009) Temperature-mediated outbreak dynamics of the invasive bryozoan Membranipora membranacea in Nova Scotian kelp beds. Mar Ecol Prog Ser 390:1-13

Scheltema RS, Williams IP (1982) Significance of temperature to larval survival and length of development in Balanus eburneus (Crustacea: Cirripedia). Mar Ecol Prog Ser 9:43-49

Scripps Institution of Oceanography (1960-1995) Surface water temperatures, salinities, and densities at shore stations, United States West Coast, 1956-1994. Data Reports, University of California, San Diego

Shulman MJ, Ogden JC, Ebersole JP, McFarland WN, Miller SL, Wolf NG (1983) Priority effects in the recruitment of juvenile coral reef fishes. Ecology 64:1508-1513

Snyder MA, Sloan LC, Diffenbaugh NS, Bell JL (2003) Future climate change and upwelling in the California Current. Geophys Res Lett 30:1823 doi:10.1029/2003GL017647

Editorial responsibility: Richard Osman, Edgewater, Maryland, USA
Sorte CJB (2010) Climate change, species invasions, and the composition of marine communities. PhD thesis, University of California, Davis

Sorte CJB, Fuller A, Bracken MES (2010a) Impacts of a simulated heat wave on composition of a marine community. Oikos 119:1909-1918

Sorte CJB, Williams SL, Zerebecki RA (2010b) Ocean warming increases threat of invasive species in a marine community. Ecology 91:2198-2204

Sorte CJB, Jones SJ, Miller LP (2011) Geographic variation in temperature tolerance as an indicator of potential population responses to climate change. J Exp Mar Biol Ecol 400:209-217

Stachowicz JJ, Whitlach RB, Osman RW (1999) Species diversity and invasion resistance in a marine ecosystem. Science 286:1577-1579

Stachowicz JJ, Terwin JR, Whitlatch RB, Osman RW (2002) Linking climate change and biological invasions: ocean warming facilitates nonindigenous species invasions. Proc Natl Acad Sci USA 99:15497-15500

Sutherland JP (1974) Multiple stable points in natural communities. Am Nat 108:859-873

Sutherland JP (1978) Functional roles of Schizoporella and Styela in the fouling community at Beaufort, North Carolina. Ecology 59:257-264

Sutherland JP, Karlson RH (1977) Development and stability of the fouling community at Beaufort, North Carolina. Ecol Monogr 47:425-446

Svane I, Young CM (1989) The ecology and behaviour of ascidian larvae. Oceanogr Mar Biol Annu Rev 27:45-90

Vitousek PM, Mooney HA, Lubchenco J, Mellilo JM (1997) Human domination of Earth's ecosystems. Science 277: 494-499

Walther GR, Post E, Convey P, Menzel A and others (2002) Ecological responses to recent climate change. Nature 416:389-395

Wendt DE (2000) Energetics of larval swimming and metamorphosis in four species of Bugula (Bryozoa). Biol Bull 198:346-356

Willis CG, Ruhfel BR, Primack RB, Miller-Rushing AJ, Losos JB, Davis CC (2010) Favorable climate change response explains non-native species' success in Thoreau's woods. PLoS ONE 5:e8878

Wolter K (2010) Multivariate ENSO index (MEI). Earth System Research Laboratory, NOAA, www.esrl.noaa.gov/ psd/people/klaus.wolter/MEI/mei.html

Yund PO, Stires A (2002) Spatial variation in population dynamics in a colonial ascidian (Botryllus schlosseri). Mar Biol 141:955-963

Zerebecki RA, Sorte CJB (2011) Temperature tolerance and stress proteins as mechanisms of invasive species success. PLoS ONE 6:e14806

Submitted: September 10, 2010; Accepted: May 26, 2011 Proofs received from author(s): August 14, 2011 